\title{
Study on Apple Marketing Model Based on Modern Aksu Region in Xinjiang
}

\author{
Xuemei Peng \\ Tarim university school of economics and management, xinjiang aksu 843300
}

Keywords: Aksu; Apple marketing; Countermeasure

\begin{abstract}
Aksu is located in the southern Xinjiang region of Xinjiang Uygur Autonomous Region. Aksu is a temperate continental arid climate in temperate continental region. It is suitable for the production of apples for more than 2,600 hours, light, temperature and water. However, with the increase of Apple's production, Apple sales at any time are becoming more and more serious, becoming a major impediment to the further development of the Aksu apple industry. Therefore, by analyzing the present situation of Apple's marketing in Aksu, the author puts forward two marketing models suitable for Aksu's development and the countermeasures to reconstruct the two models, and hopes to build up the modern apple marketing model of Aksu region.
\end{abstract}

\section{Introduction}

Aksu is located in the southern Xinjiang region of Xinjiang, where the temperature difference is large, the light is abundant, the soil is fertile, so that the sugar content of the apple is high, the sugar is about eighteen degrees, the taste is particularly sweet; moreover, most of the region uses glacier snow water to irrigate, sand soil culture and other characteristics, so that apple fruit kernel part sugar accumulation into a transparent shape, forming the world's unique "sugar core" Fuji apple. Although Aksu area has good apple products, but the marketing channel has become the key point of Apple's development in Aksu area. Over the years, Apple produces and sells apples in the Aksu area, but sales aren't directly proportional to output, while Apple produces less profit for farmers because Apple's added value is too low, and a lot of profits are earned by middlemen.

\section{Problems existing in Apple's marketing mode in Aksu region of Xinjiang}

In comparison with the output and sales volume of the last three years in the Aksu area, production and marketing have been basically balanced and there is no problem on the surface. However, the profit of the fruit farmers is not too high by comparing the input and income of the fruit farmers in recent 3 years, the reason, mainly fruit growers, is that Apple is selling directly to middlemen when it is ripe for the season, and it is hard to sell the apples at this time due to seasonality. This kind of marketing model directly through intermediaries, the main part is the fruit grower-middleman, the process is not complicated, but the main problem is that the fruit farmer does not get too much profit, the real profit is mostly earned by the middleman, so, to change this model, it is necessary to restructure the fruit farmers to really get an affordable marketing model.

At present, Aksu region has taken an enterprise acquisition, then sold by the enterprise to the middlemen's sales mode, such a marketing model does not establish its own marketing network, and in the deep processing of products is not, mainly or sell fresh fruit, this makes the product's added value is very low, although some areas are trying to further processing in apple processing, but is still in apple cider vinegar and apple crisp, project report research, discussion and demonstration phase, has not formally put into production and production efficiency. Therefore, these fruit enterprises in the product processing and marketing strategy, there are many shortcomings and need to improve.

Combined with the seasonal characteristics of apple planting, growth and results, the sale of fresh fruit alone is very bad for the farmers, such as the Aksu area, once the damage to the natural disaster in hailstorm weather, the basic of Apple is all scrapped, basically is the residual fruit, can only be sold to the enterprise that makes jam at a very low price, this makes the fruit farmer's 
income greatly reduced, seriously hurt the enthusiasm of the fruit farmers. If you can have your own fruit company to process or adopt a good marketing mode, the residual fruit will also maintain the price consistent with the market price, protect the benefit of the fruit farmers, so that it can keep Aksu out of the production and quality of sustainable development, in order to do a strong Aksu area Apple industry to establish the foundation.

\section{An Apple Marketing Model in Aksu in Xinjiang}

Aksu area has abundant tourism resources, people will also visit the idyllic scenery, with the aid of tourism agriculture to promote the development of Apple in the Aksu area is a good model. However, in order to establish tourism agriculture in economically poor areas, due to too weak infrastructure, early infrastructure spending is significant and needs to be promoted and directed by the local management department. According to the definition of tourism agriculture, tourism agriculture is the combination of agriculture and tourism, the use of agricultural landscape and rural space attract tourists to come to a new type of agricultural operation form, that is to develop tourism products based on the extensive agricultural resources such as agriculture, forestry, animal husbandry, vice, fishery and so on, and provide the tourists with the characteristic service tourism industry. Aksu apple orchard has such conditions, suitable for the development of tourism agriculture. In view of the current situation of agricultural tourism abroad, according to the characteristics of agricultural tourism, orientation, management and other aspects, and in combination with the specific situation of the agricultural one-teacher apple orchard, the development model of the agronomist tourism agriculture mainly can adopt the following two modes, one is the traditional sightseeing tourism agriculture, mainly to avoid the familiar agricultural production process of the city, in the city near the suburbs or the scenic spot, open the characteristic orchard, vegetable garden, tea garden, flower garden, etc., let the visitors enter the inner pick fruit, pull, admire the flowers, the tea, enjoy the idyllic pastoral pleasures. Another is leisure resort type tourism agriculture, mainly use different agricultural resources, such as forest, pasture, orchard and so on, attract tourists to go on vacation, carry out agricultural experience, natural ecology taste, fishing, game taste, accommodation, vacation, recreation and other kinds of sightseeing, leisure vacation travel activities. Aksu area may rely on apple cultivation to set up some tourism facilities around the world, when planting time can let frequent travel casual customers themselves choose to grow a named apple tree, waiting for its growth and the results, and the natural share of the destiny of the leisurely and carefree. As soon as Apple is ripe, advertise in the newspaper, attract tourists to the farm to pick fruit holidays, the city people to eat, the fruit casually eat, tired can be in the trees to rest, breathe fresh air, listen to the song of the birds, until the sun is slanting, people can also spend a night in the orchard, taste the orchard owner prepared to do not have the style dinner, enjoy a chic vacation. Through the experience of the people in Aksu, a farmer, let them know more about the apple of the farmers, like the apple of the agronomist, use word of mouth to publicize the special features of Aksu Apple, the agronomist, so as to enlarge the brand effect of Apple in the tourism. The operation of this model can be carried out first by a group of six regiments. Under the vigorous deduction of the management department of NON, the two modes of setting up traditional sightseeing and leisure resorts in the apple orchard drive the sale of apples.

This model is based on the assistance of the relevant departments, the establishment of enterprises with the processing, storage and marketing of agricultural products, around an industry or a product, the implementation of the production, processing and sales integration of a agricultural product industrialization management mode. The advantage of this" enterprise + base + farmer "model is to reasonably arrange the quantity and scale of the enterprise with the help of the management department of the agronomist, prevent excessive competition, divide the cake more and smaller, besides, enterprises can set off from the natural and economic conditions all over the country according to the needs of the market, build a suitable production base, and realize the efficient docking of the market and resources, thus saving the transaction cost. Aimed at Apple's current marketing model in the Aksu area, it is mainly to make the existing fruit enterprises stronger, increase investment efforts to build processing production line, achieve a variety of ways of apple 
processing as soon as possible, and sign long-term supply-off contracts with fruit growers, and protect the interests of the fruit farmers. This kind of enterprise-centered marketing model has two main advantages: first, government-related policy support and agricultural information support, and grant some financial subsidies and planting guidance for the fruit farmers of Aksu area, and can concentrate on major events with the help of the government departments. Secondly, the formation of cluster fruit companies, the marketing of Apple in Aksu area is a good platform, the Aksu area of the apple can be bought by the fruit company, unified sales and processing. Enterprises can root out different levels of development and further processing of fruit products, improve the added value of the products and increase the revenue of fruits and peasants.

\section{The specific ideas of Apple's marketing model in Aksu's area}

First, the relevant departments of Aksu should provide overall planning guidance for the orchards of each league, and provide preferential policies such as agricultural low-interest credit and tax breaks for areas with conditions to carry out agricultural tourism; intensify investment efforts and improve the local tourism infrastructure as soon as possible. Second, standardize the operation of agricultural tourism. We will actively encourage staff and workers to set up agricultural tourism association and standardize the operation and management of agricultural tourism. To carry out agricultural tourism shall be registered with the tourism management department at all levels and issue a certificate after passing the examination. For example, reception of tourists must be non-agricultural productive activities; the whole or most part of the food must be the product of the farm or local farm; the sale price should be lower than the wholesale price; in order to ensure the safety of tourists, the tourists shall have the limited scope of their activities and the ability to take into consideration the ability of tourists to stay in places, explain the equipment in advance to the tourists, especially the use of electrical appliances. Third, improve the quality of tourism products. Carefully plant, manage scientific management to improve the quality of the orchard, let the person who comes here to taste the best apple; develop a variety of suitable portable Apple products as soon as possible so that the tourists can be fully loaded. Fourth, improve the tourism environment. Efforts are made to collate the orchard, improve the overall features of the apple orchard, strengthen the skills training of practitioners, improve service consciousness, discard some bad habits; increase the infrastructure construction of roads, hotels, restaurants, communications, toilets and other infrastructure, improve the filthy, chaotic and bad situation of the pass-pass orchard; the vast majority of agricultural tourism practitioners must realize that the majority of tourists are urban residents, and they must ensure that they adapt to the health and safety requirements of urban residents in the food, housing and line, and on the basis of this, the agricultural taste of the elements such as shopping, entertainment and tour. Five, the formulation of suitable for each region of fruit purchasing, sales system, earnestly implement the development of each fruit company, according to the planting area of the group, production to each fruit company to do detailed planning. Sixth, to have the conditions to do fruit processing of fruit products enterprises, relevant departments to give project funds and policy support, all-round guidance, to ensure the smooth implementation of the fruit processing project. Its seven, according to the geographical location, natural environment, planting way and technology are different, the growth of apples existence quality differences, so each fruit company to divide its own apples, to the quality and price of the same, to have obvious packaging different from each region's apple. Eight, Aksu should make an overall plan to select some qualified enterprises to expand the scale, to do a large number of leading enterprises, in order to support the development of the region's apple industry, avoid duplication of investment construction. Nine, each fruit company should try to do chain store and supermarket directly, reduce intermediate link, try to improve fruit enterprise and fruit farmer's benefit; to strictly control the unity of price of supermarkets and chain stores in the same region, can not appear price chaos, affect the trust of consumers. 


\section{Conclusion}

Aksu region, as the major apple producing region in Xinjiang, is famous for its cultivation of Fuji, Iced Apple, home and abroad, the development of Apple's apple should increase production, increase the value added, improve marketing mode, meet the Aksu's actual marketing mode, strive to achieve Aksu's industrialization road and brand culture strategy, really do big apple, let the fruit farmers get rich, thus driving the development of agricultural economy in Aksu area.

\section{References}

[1] Yan 1, Cui Yan Bin. An Exploration of Apple's Marketing Pattern in Aksu Region of Xinjiang. Shihezi University, 2012.

[2] Fig. 3, Cui Yanbin, Li Wanming. Research on apple marketing model of XPCC's apple marketing model. Xinjiang Agricultural Reclamation Economy, 2012 (05): 75-78.

[3] Distance to the town station. The modernization of traditional marketing mode of regional characteristic industry _ to Yanbian apple pear as an example. Business, 2016 (44): 45-46.

[4] Jia Shu E, Li Hong. Investigation and analysis of forest fruit logistics mode in Zepu County. Stone Local Economy, 2016 (07): 56-57. 